\title{
Pelatihan Aplikasi Media Pembelajaran Daring Bagi Guru SMA NW Narmada
}

\author{
Sri Erny Muliyani, Supriadin
}

Fakultas Ilmu Keolahragaan dan Kesehatan Masyarakat Universitas Pendidikan Mandalika

Email: sriernymuliyani@ikipmataram.ac.id

\begin{abstract}
Abstrak. Kegiatan Pengabdian kepada Masyarakat (PkM) ini memiliki tujuan untuk memberikan guru SMA NW Narmada sebuah keterampilan tentang pembelajaran secara online agar bisa melaksanakan kegiatan belajar mengajar dengan siswanya langsung melalui daring. Hampir sebagian guru yang mengajar tidak mengggunakan kegiatan pembelajaran secara daring karena kurang memiliki pengalaman dalam penerapan media pembelajaran secara online. Dalam pelatihan ini metode pelaksanaannya dengan tahapan ceramah dan praktik, yaitu guru diberikan pemahaman dan pengenalan tentang pembelajaran daring, penjelasan media pembelajaran dengan aplikasi google classroom, serta guru melaksanakan praktik latihan menggunakan aplikasi google classroom. Berdasarkan pelatihan yang sudah dilaksanakan maka dapat disimpulkan bahwa pelatihan ini dapat berjalan dengan baik dan lancar dimana peserta pelatihan mampu mengaplikasikan google classroom serta memanfaatkan media tersebut dalam pembelajaran.
\end{abstract}

\section{Kata Kunci: Pelatihan, Pembelajaran Jaringan, Google Classroom}

Abstract. This Community Service Activity (PkM) aims to provide NW Narmada High School teachers with skills about online learning so they can carry out teaching and learning activities with their students directly through courage. Almost some teachers who teach do not use learning activities boldly because they lack experience in implementing online learning media. In this training, the implementation method is with lecture and practice stages, namely the teacher understanding and introduction to bold learning, explaining learning media with the google classroom application, and the teacher carrying out practical exercises using the google classroom application. Based on the training that has been implemented, it can be argued that this training can run well and smoothly where the training participants are able to apply Google classes and take advantage of these media in learning.

Keywords: Training, Network Learning, Google Class

\section{PENDAHULUAN}

Pelaksanaan pembelajaran di masa pandemik covid-19 ini memberikan pengaruh yang sangat besar terhadap pendidikan, khususnya terhadap profesi guru dalam melaksanakan tugas yang sangat berat yaitu salah satunya memiliki tanggung jawab mendorong, membimbing, dan memberikan fasilitas belajar terhadap anak didiknya. Berdasarkan surat edaran dari pemerintah bahwa proses pembelajaran dialihkan yang awal proses pembelajaran dilakukan di sekolah menjadi pembelajaran dari rumah melalui pembelajaran online.

Guru dalam perannya tersebut harus mampu menciptakan pembelajaran yang efektif dan kondusif. Guru diharapkan dapat menerapkan metode yang tepat dalam pembelajaran agar siswa terhindar dari kebosanan dan dapat menciptakan kondisi belajar yang efektif, efisien dan interaktif. Media pembelajaran yang kreatif dan inovatif dalam peningkatan kualitas pembelajaran dapat meningkatkan motivasi dan hasil belajar siswa, oleh karena itu hendaknya pendidik harus mampu melaksanakan pembelajaran yang berbasis online atau daring.

Pembelajaran dalam jaringan, salah satu cara yang dapat dilakukan oleh pendidik adalah dengan memanfaatkan alat canggih dari handphone, komputer ataupun laptop yang terkoneksi dengan jaringan internet. Berbagai aplikasi dalam gadget dapat dimanfaatkan untuk melaksanakan kegiatan proses belajar mengajar agar lebih terupdate, dan memudahkan pendidik memberikan 
pembelajaran serta mengurangi kebosanan siswa dalam belajar.

Tugas guru dalam pembelajaran di masa pandemik covid-19 harus melakukan pembelajaran secara online. Keadaan ini memaksa guru sekolah NW Narmada mau tidak mau harus melaksanakan pembelaran online. Beberapa faktor yang menjadi kendala bagi guru sekolah NW Narmada antara lain kurangnya pengalaman guru dalam pembelajaran daring sehingga tidak pernah melaksanakan pembelajaran secara online, tidak semua guru memiliki handphone android, dan kurangnya kemampuan guru yang memiliki handphone dalam membeli kuota internet, serta kurangnya kemampuan guru dalam mengoperasikan handphone android.

\section{METODE PELAKSANAAN}

Berdasarkan permasalahan yang ada pada latar belakang di atas, terkait proses pembelajaran guru NW Narmada dalam perannya untuk mendorong dan mendampingi siswa belajar secara online, maka metode pelaksanaan dalam pelatihan ini adalah menggunakan metode ceramah dan praktik, dengan tahapan sebagai berikut:

1. Mengenal pembelajaran daring secara umum. Pada kegiatan ini, guru diberikan pengenalan terhadap pembelajaran dalam jaringan (daring). Pembelajaran daring adalah pembelajaran yang dilakukan melalui jaringan internet dengan menggunakan media berupa WhatsApp, Zoom Meeting, Google classroom, dan aplikasi lainnya yang sejenis bisa digunakan dalam proses pembelajaran.

2. Penjelasan tentang media pembelajaran daring dengan menggunakan aplikasi google classroom. Pada kegiatan ini, guru diberikan pemahaman dan pengenalan tentang aplikasi google classroom, mulai dari informasi perangkat yang digunakan sebagai media dalam proses pembelajaran daring seperti laptop, atau menggunakan handphone. Selanjutnya jika menggunakan hp maka aplikasi google classroom yang harus didownload dengan menggunakan playstore serta internet diusahakan tetap tersambung.
3. Tahapan terakhir, praktik latihan penggunaan aplikasi google classroom. Pada kegiatan ini guru melaksanakan praktik pembelajaran daring dengan media pembelajaran google classroom. Beberapa praktik yang dilakukan yaitu membuka aplikasi google classroom, membuat kelas, penjelasan join kelas, dan mengupload materi.

Untuk semua tahapan, selama pelatihan guru diberikan kesempatan untuk tanya jawab, dan tim terus memberikan informasi, penugasan, serta monitoring.

\section{HASIL DAN PEMBAHASAN}

Kegiatan pengabdian ini dilaksanakan berdasarkan hasil observasi di SMA NW Narmada, bahwa sebagaian besar guru mengajar tidak menggunakan kegiatan pembelajaran secara daring karena kurang memiliki pengalaman dalam penerapan media pemelajaran secara online. Berdasarkan hal tersebut, tim pelaksana pengabdian kemudian diskusi dan merencanakan kegiatan pelatihan yang akan dilakukan. Dari proses pelaksanaan pengabdian kepada Masyarakat dengan kegiatan pelatihan menggunakan aplikasi media pembelajaran bagi guru SMA NW Narmada, didapatkan hasil sebagai berikut:

1. Pembelajaran daring secara umum, dimana pada bagian kegiatan ini materi yang disampaikan tentang berbagai macam media pembelajaran yang bisa dipergunakan dalam pembelajaran daring yaitu media berupa WhatsApp, Zoom Meeting, Google classroom, dan aplikasi lainnya yang sejenis.

2. Pembelaran daring menggunakan media aplikasi google classroom, dimana pada bagian kegiatan ini materi yang disampaikan berupa hardware dan software yang digunakan untuk aplikasi google classroom. Hardware yang bisa digunakan adalah dengan menggunakan laptop atau handphone, sedangkan software yang digunakan adalah aplikasi google classroom didownload menggunakan playstore untuk harware yang menggunakan handphone dan fasilitas internet harus tetap tersambung. 
3. Praktek aplikasi google classroom, kegiatan dibagian ini peserta atau guru SMA NW Mataram yang telah mendownload atau masuk dalam aplikasi google classroom maka dilanjutkan dengan membuat kelas untuk mata pelajaran yang diampu masing masing peserta, dilanjutkan dengan membuat join kelas untuk murid pada mata pelajaran yang diampu, sekaligus menginputkan materi yang sudah dibuat oleh peserta menggunakan file.

Semua kegiatan dilakukan pendampingan oleh tim pengabdian pada masyarakat, agar para guru dapat menyelesaikan kegiatan pelatihan dengan menerima informasi, penugasan dan monitoring dari tim pengabdian pada masyarakat.

Secara umum, para peserta pelatihan yaitu guru SMA NW Narmada menanggapi secara positif kegiatan pelatihan ini, dibuktikan dengan proses interaktif antara penyaji dan peserta selama pelaksanaan pelatihan.

\section{SIMPULAN}

Melihat dari hasil dan pembahasan kegiatan pengabdian kepada masyarakat ini, maka kami dapat menyimpulkan bahwa peserta sangat antusias terhadap kegiatan pengabdian dengan melihat respon positif dari para guru mengikuti pelatihan. Selanjutnya pendampingan pelatihan aplikasi media pembelajaran daring bagi guru SMA NW Narmada sudah berjalan dengan baik dan lancar serta mencapai target dari yang direncakan yaitu guru SMA NW Narmada mampu mengaplikasikan media pembelajaran daring menggunakan aplikasi google classroom.

\section{DAFTAR PUSTAKA}

Aji, W., Dewi, F., Kristen, U., \& Wacana, S. (2020). Dampak Covid-19 TerhadapImplementasi Pembelajaran Daring Di. 2(1), 55-61.

Azhar Arsyad. 2013. Media Pembelajaran. Jakarta: Rajagrafindo Persada.
Isman, M. (2017). Pembelajaran Moda dalam Jaringan (Moda Daring). The Progressive and Fun Education Seminar, 586-588.

Jamaluddin, D., Ratnasih, T., Gunawan, H., \& Paujiah, E. (2020). PembelajaranDaring Masa Pandemik Covid-19 Pada Calon Guru: Hambatan, Solusi danProyeksi. Karya Tulis Ilmiah UIN Sunan Gunung Djjati Bandung.

Wicaksono, V. D., \& Rachmadyanti, P. (2016). Pembelajaran Blended Learning melalui Google classroom di Sekolah Dasar. Seminar Nasional PendidikanPGSD UMS \& HDPGSDI Wilayah Timur. 